\title{
Validação de sistema de parâmetros técnicos de mobilidade urbana aplicados para sistema cicloviário
}

\author{
Validation of technical parameters to assessment of \\ urban mobility applied to cycling infrastructure
}

Vinicius Tischer

\section{Resumo}

O objetivo da pesquisa foi o de gerar uma base de análise quantitativa para subsidiar uma avaliação integrada da infraestrutura cicloviária inserida no contexto de mobilidade urbana das cidades. A metodologia utilizada deu ênfase a pesquisa e o desenvolvimento de parâmetros estatístico-matemáticos que explicitam a continuidade ou a fragmentação, densidade, e funcionalidade de um sistema cicloviário utilizando estudo de caso das cidades de Balneário Camboriú/SC e Itajaí/SC para validar os índices e parâmetros propostos. Ambas as cidades possuem um sistema implementado de infraestrutura cicloviário e projetos de expansão desta, o que facilitou a comparação entre elas. Os resultados obtidos mostraram-se positivos, com indicadores aderentes e sensíveis para a quantificação da qualidade do sistema cicloviário das cidades, subsidiando o planejamento urbano e adoção e monitoramento de metas. 0 desenvolvimento do IMCiclo (Índice de Mobilidade Cicloviária) permitiu, de forma objetiva e simplificada, classificar a qualidade do sistema cicloviário contribuindo para a difusão da necessidade de mensuração das condições da infraestrutura cicloviária. Foi possível observar claramente as diferenças entre as cidades estudadas, onde Balneário Camboriú atingiu os melhores índices.

Palavras-chave: Mobilidade urbana. Infraestrutura cicloviária. Planejamento urbano integrado. Indicadores de mobilidade urbana. Bicicletas.

\section{Abstract}

The purpose of the research was to generate a quantitative analytical basis to support an integrated assessment of cycling infrastructure inserted in urban mobility context of cities. The methodology emphasized the research and development of statistical-mathematical parameters that explain the continuity or fragmentation, density, and functionality of cycling system using case study of the cities of Balneário Camboriú and Itajaí,

VT é Engenheiro ambiental, Doutorando, e-mail: tischer@edu.univali.br 
Estate of Santa Catarina to validate the indexes and parameters proposed. Both cities have an implemented system of cycling infrastructure and projects for expansion of it, which facilitate the comparison between them. The results were positive, with adherents and sensitive indicators able to quantify the quality of the cycling system of cities, subsidizing urban planning and adoption and monitoring goals. The development of IMCiclo (Cycling Mobility Index) allowed in an objective and simplified way, to rate the quality of the cycling system contributing to the spread of the need to measure the conditions of cycling infrastructure. It was possible clearly observe the differences between the cities studied, where Balneário Camboriú reached the best rates.

Keywords: Urban mobility. Cycling infrastructure. Integrated urban planning. Urban mobility indicators. Bicycles.

\section{Introdução}

A concepção de mobilidade urbana vem sofrendo mudanças com novos anseios por parte da população brasileira, que, no geral, deseja cada vez mais a utilização de meios alternativos para o deslocamento, especificamente o uso de bicicletas (Neckel, et al, 2015; Silva, 2015). Até recentemente o uso de bicicletas era visto quase que exclusivamente para lazer, utilizadas para passeio e usos de fim de semana (Transporte Ativo, 2015). Apesar do código de trânsito brasileiro trazer diretrizes para a utilização de bicicletas, apenas no ano de 2012 foi promulgado o Plano Nacional de Mobilidade Urbana (Lei 12.587/2012).

Embora a implementação do plano tenha caráter positivo acerca desta tendência, poucos investimentos públicos são realizados além de questionamentos de grupos de comerciários/empresários acerca de possíveis impactos negativos para os negócios e economia resultante da ampliação da infraestrutura cicloviária, redução dos estacionamentos, como citado para a cidade de São Paulo, por exemplo (Maruyama \& Simões, 2014; Allis, 2015).

Novos estudos, entretanto, apontam que isso não é válido para a maioria dos locais, como por exemplo, em Nova York foi constatando um aumento em 49\% no faturamento do comércio de varejo a partir da instalação de ciclovias (NYC, 2012). $\mathrm{Na}$ cidade de Melbourne, Lee (2008) constatou que o ciclismo gera 3,6 vezes mais em compras. Outros exemplos factíveis são dados pela valorização imobiliária, sendo contabilizados valores de incremento de pelo menos US\$ 8,8 mil no valor de propriedades com ciclovia localizada dentro de 50 metros (Racca \& Dhanju, 2006).

Além do mais, outros trabalhos vêm apontando o que de certa forma já se supunha através da expressão popular: Quer bicicletas? Construa ciclovias. A frase faz referência de que a partir da implementação de infraestrutura cicloviária, os usuários naturalmente irão aderir (Dill \& Carr, 2003). Esta hipótese foi confirmada recentemente pelo estudo do National Institute for Transportation and Communities (NITC, 2014), onde após um ano de instalação do sistema, o percentual de usuário de bicicleta subiu entre $21 \%$ e $171 \%$, nas cinco cidades estudadas, por exemplo.

0 estudo mostra ainda, dados interessantes sobre a segurança, apontando que $40 \%$ das mortes de ciclistas estão atreladas a acidentes onde o ciclista é atingido por trás, por veículos, geralmente em vias arteriais de fluxo intenso, alertando para a importância da separação de faixas, e que naturalmente ciclofaixas imputam um risco maior do que ciclovias. Além disso, os dados do estudo mostraram que a sinalização para ciclistas influencia no comportamento destes, onde cerca de 77-93\% dos ciclistas respeitou a sinalização e não avançou em sinal vermelho, para as cidades analisadas (NITC, 2014).

Um sistema cicloviário consiste na infraestrutura de mobilidade para bicicletas e a sua implementação pode se dar por diferentes meios construtivos. Destacam-se aqui as definições de ciclovia, ciclofaixa, ciclorrota e espaço compartilhado que comporão o sistema cicloviário, sendo descritos abaixo, segundo Gondim (2010); LABTRANS (2012); e CET (2016): 
- Ciclovia: Além de designar toda a infraestrutura projetada para a circulação de bicicletas, refere-se a um espaço exclusivo para o tráfego de bicicletas, sendo isolada fisicamente. Uma das vantagens mais importantes desta tipologia é a maior segurança ao ciclista, uma vez que aumenta a proteção do ciclista do tráfego rápido e intenso de veículos automotores;

- Ciclofaixa: Faixa da via de rolagem ou calçadas destinadas à circulação de bicicletas, sendo sinalizadas horizontalmente com pintura e/ou tachões, porém não são isoladas fisicamente, como no caso da ciclovia; Entre as vantagens desta está o baixo custo, uma vez que se utiliza da infraestrutura viária já existente;

- Espaço compartilhado: Faixas para a circulação de dois ou mais modais, como bicicleta e pedestre ou bicicleta e veículo motorizado. O Código de trânsito (Lei 9.503/1997) aponta: “...a circulação de bicicletas deverá ocorrer, quando não houver ciclovia, ciclofaixa, ou acostamento, ou quando não for possível a utilização destes, nos bordos da pista de rolamento, no mesmo sentido de circulação regulamentado para a via, com preferência sobre os veículos automotores..."

- Ciclorrota: Consiste em caminho, sinalizado ou não, selecionados para constituir uma rota recomendada para o ciclista trafegar. Bicicletas e outros veículos dividem a mesma via, mas a preferência é da bicicleta.

Para um melhor entendimento do sistema cicloviário discriminado acima cabe a definição de outros conceitos importantes para o trabalho. Rodrigue et al. (2006) destacam a relação entre acessibilidade e conectividade, onde a primeira é tida como medida da capacidade de um local de ser atingido, ou para alcançar locais diferentes. A conectividade representa o nível em que os locais estão ligados uns aos outros. Estas definições são complementares e assim, compreender a conectividade de uma rede permite compreender a acessibilidade das localidades desta rede. Redes de transporte existem para conectar localidades, e, portanto, uma melhor rede de transportes permite que mais pessoas se desloquem para mais lugares mais facilmente.
0 aumento da conectividade de uma rede pode reduzir as distâncias de viagem para todos os modais de transporte, incluindo caminhar e andar de bicicleta. Um benefício adicional de uma maior conectividade é ter mais possibilidades de rotas para se escolher. Um ciclista, por exemplo, pode escolher uma rota ligeiramente mais longa se esta possuir ciclovia, uma rua com menos tráfego, ou trecho com relevo menos acidentado. Quantificar a acessibilidade e conectividade de uma rede permite, portanto, compreender sua estrutura e relacionar pontos de interesse, gargalos e subsidiar ações (Pildes, 2014).

Para o trabalho, será adotado ainda, o conceito de fragmentação, que pode ser entendida como a falta de continuidade do sistema cicloviário, sendo comum nos municípios brasileiros a construção de rotas para ciclistas isoladas, carecendo de conexão com outros trechos existentes. Isso fornece uma insegurança aos ciclistas e um não convencimento para a adesão de novos usuários, sendo considerado um grave impedimento para o ciclismo utilitário (Rau, 2012; Marlin, 2008).

Segundo Schoner \& Levinson (2014) estudos avançaram significativamente a compreensão da qualidade da infraestrutura para bicicletas, incluindo técnicas de modelagem e aperfeiçoamento do sistema cicloviário. Entretanto, a funcionalidade do uso de bicicletas tem sido pouco estudada no Brasil, no que se refere à quantificação de parâmetros, planejamento, estabelecimento de instrumentos e monitoramento de metas. Isso foi constatado devido ao escasso material bibliográfico disponível em plataformas de periódicos e universidades no país.

Essa foi uma das principais motivações desta pesquisa, na qual se propôs aumentar o entendimento, com base em técnicas de estatística e matemática, de como diferentes parâmetros técnicos do sistema cicloviário podem influenciar no entendimento da mobilidade urbana em cidades, em subsídio ao planejamento urbano e melhoria da qualidade de vida da população.

Dessa forma, com o desenvolvimento de estudos fundamentados em parâmetros objetivos seria possível planejar melhor as cidades, tornando este processo mais técnico e com uma melhor eficiência e eficácia na execução de projetos urbanos. 


\section{Metodologia}

Para o desenvolvimento do estudo, o primeiro passo foi a coleta de dados. Isso se deu por meio de pesquisa bibliográfica acerca de parâmetros quantitativos aplicáveis para o desenvolvimento, monitoramento e planejamento estratégico da infraestrutura cicloviária enquanto modal alternativo de um sistema de mobilidade urbana.

A partir de revisão bibliográfica foram elencados parâmetros técnicos de conectividade da infraestrutura cicloviária usualmente empregados e respectiva metodologia de cálculo. Além disso, foram desenvolvidos índices complementares, para evidenciar a fragmentação e a cobertura do sistema cicloviário, por meio de relações matemáticas analíticas.

Com o elenco destes parâmetros foi realizada uma validação, tendo por estudo de caso dois municípios brasileiros. Foi feito um levantamento dos dados necessários para a construção dos indicadores e índices por meio de banco de dados das prefeituras municipais, associações de ciclismo e bibliografia técnica acerca do sistema viário e cicloviário, existente e projetado. Foram realizadas ainda, campanhas in situ para validar mapas/plantas existentes assim como a complementação do cadastro existente por decorrência de obras recentes na expansão das malhas cicloviárias.

A partir da coleta de dados, foi realizado um tratamento de dados em Sistema de Informação Geográfica (SIG) no caso dos dados espaciais, além da utilização de planilha eletrônica para cálculos em geral. Com isso foi possível validar e comparar os resultados, subsidiando uma discussão e análise da efetividade dos indicadores e índices propostos, além de avaliar a aderência do método para os municípios considerados na validação. A Figura 1 apresenta o procedimento adotado por meio de fluxograma.

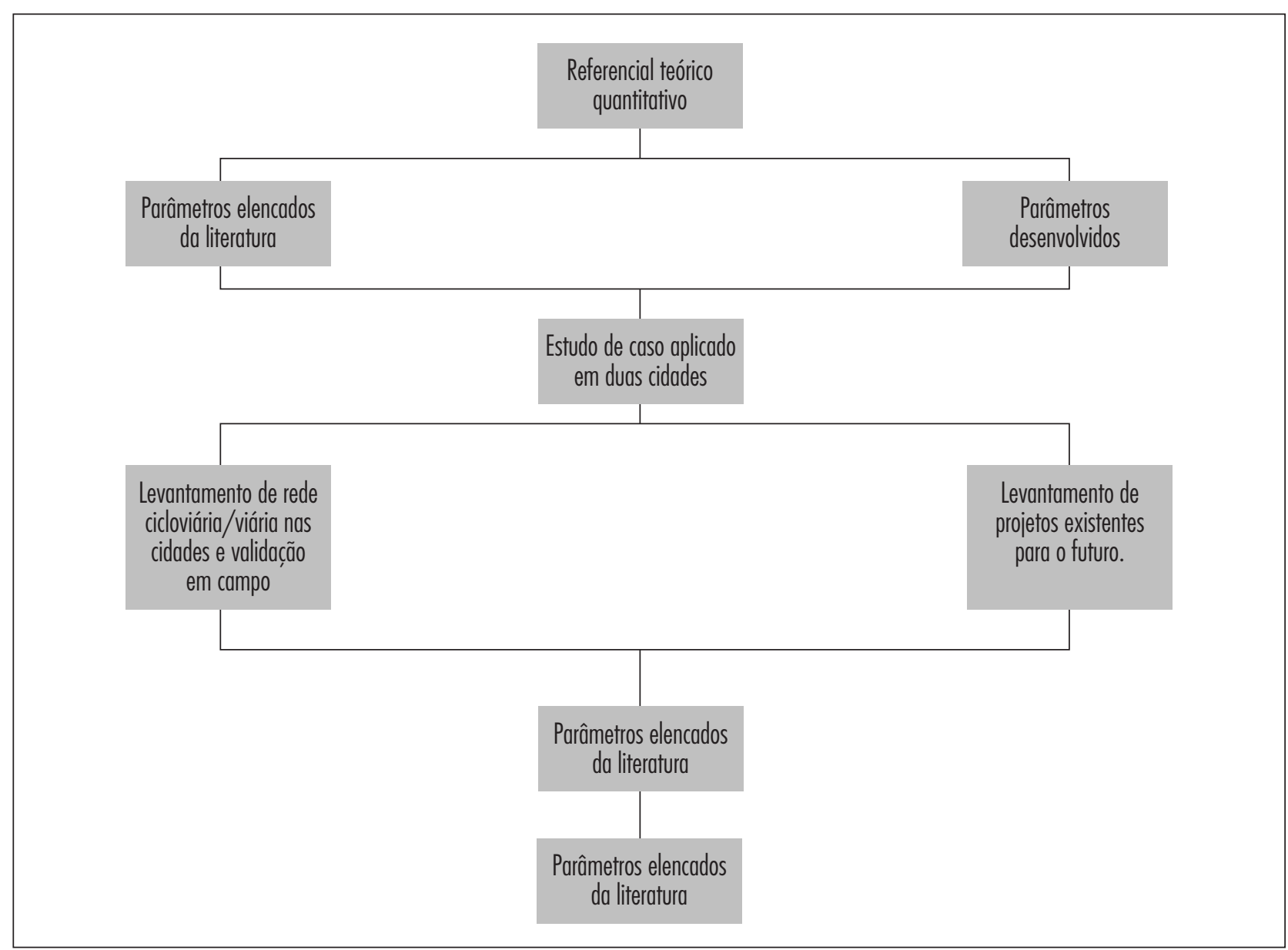

Figura 1- Fluxograma de trabalho do estudo realizado.

Fonte: 0 autor.

urbe. Revista Brasileira de Gestão Urbana (Brazilian Journal of Urban Management), 2017 set./dez., 9(3), 587-604 


\section{Área do estudo de caso}

Foram elencados dois municípios para a realização do estudo, a saber: Balneário Camboriú e Itajaí. Estes são municípios limítrofes, e situam-se no litoral centro-norte do Estado de Santa Catarina. Dados do IBGE apontam que os municípios possuem uma alta taxa de urbanização, sendo de $96,6 \%$ para Itajaí e 100\% para Balneário Camboriú, e ambos se situam na faixa de municípios entre 100-200 mil habitantes. Estimativas do IBGE, para o ano de 2014, apontam uma população total de 124.557 e 201.557 habitantes, respectivamente para Balneário Camboriú e Itajaí. A localização dos municípios é apresentada na Figura 2.

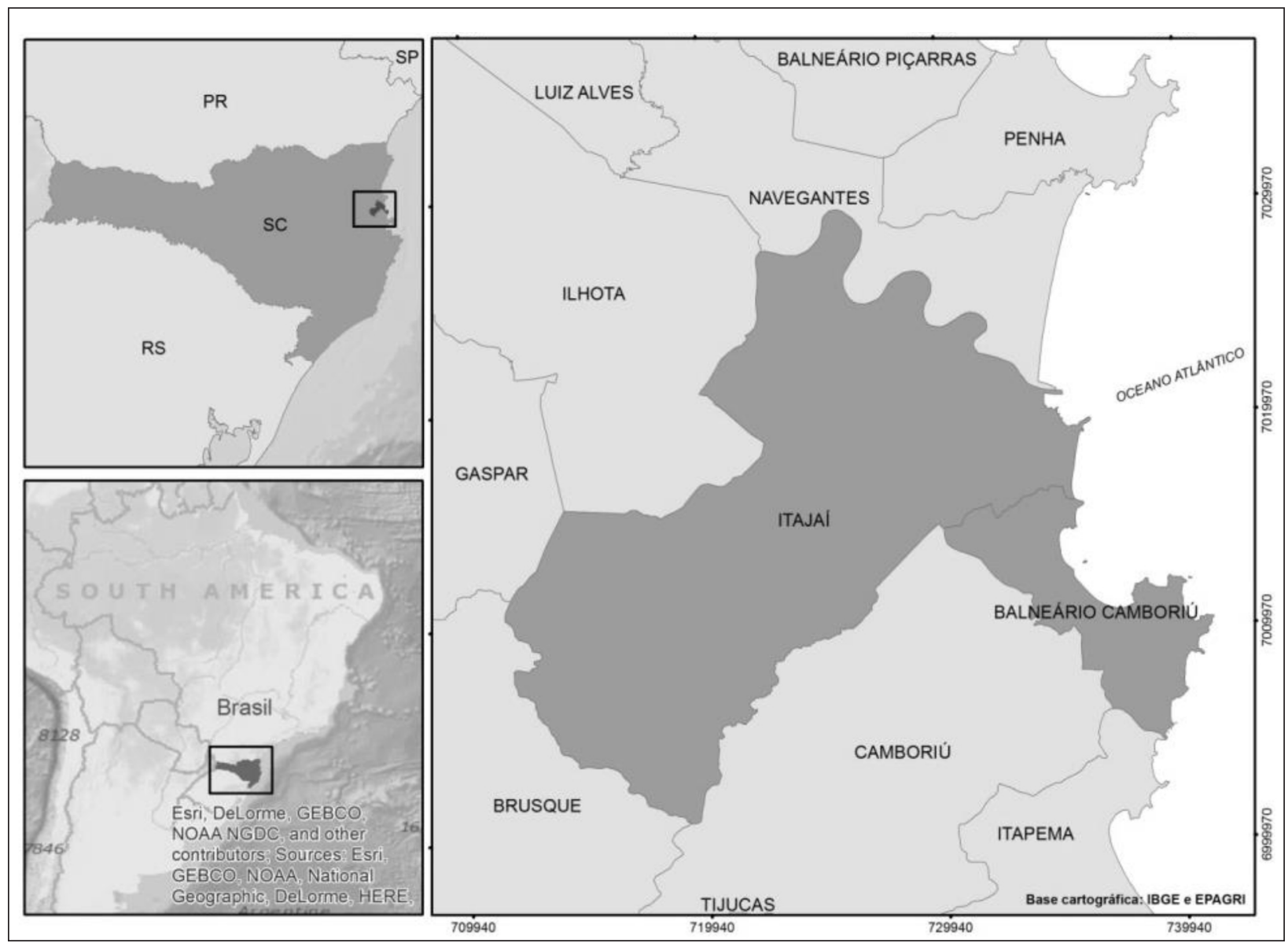

Figura 2 - Localização dos municípios de estudo.

Fonte: 0 autor.

\section{Coleta de dados}

Os dados utilizados da rede cicloviária de Balneário Camboriú foram obtidos com base nos estudos técnicos do Plano Diretor de Balneário Camboriú (PMBC, 2014) que contém os traçados atuais e projetados. Foi necessário complementar a rede do município considerando o diagnóstico da Associação de Ciclismo de Balneário Camboriú e Camboriú (ACBC), além da validação em campo realizados na cidade, atualizando o traçado da rede até o mês de julho de 2015.

Para Itajaí, apesar de não estar disponível um documento contendo a rede projetada, foi utilizada a rede proposta pela Associação dos Ciclousuários de Itajaí (CICLOAÇÃO). Os traçados também foram validados em campo a fim de atualizar a ampliação da rede. Os mapas contendo o sistema atual e proposto são apresentados nas Figuras 3, 4 e 5. 


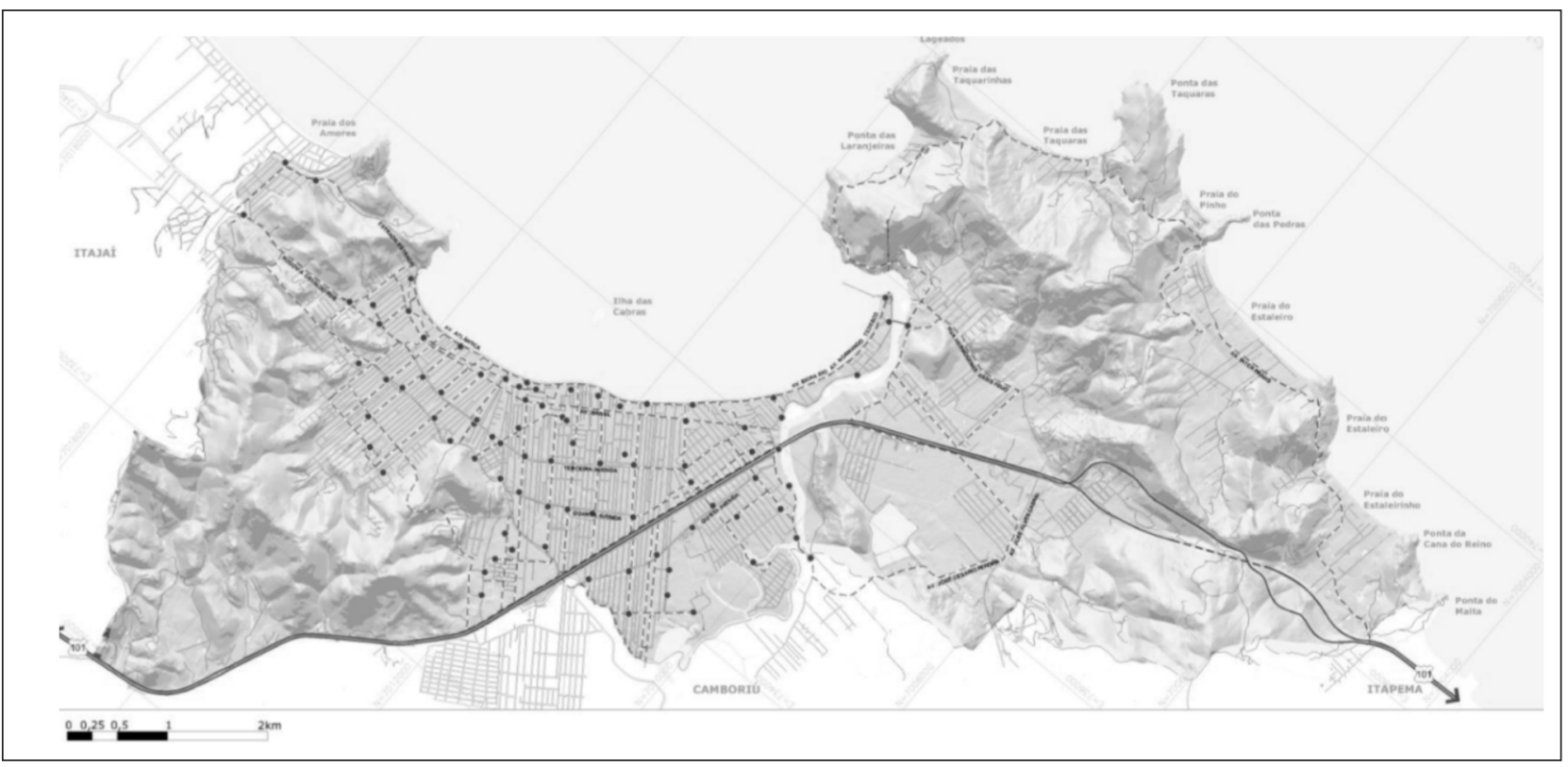

Figura 3 - Sistema cicloviário existente e projetado em Balneário Camboriú-SC.

Fonte: PMBC, 2014.

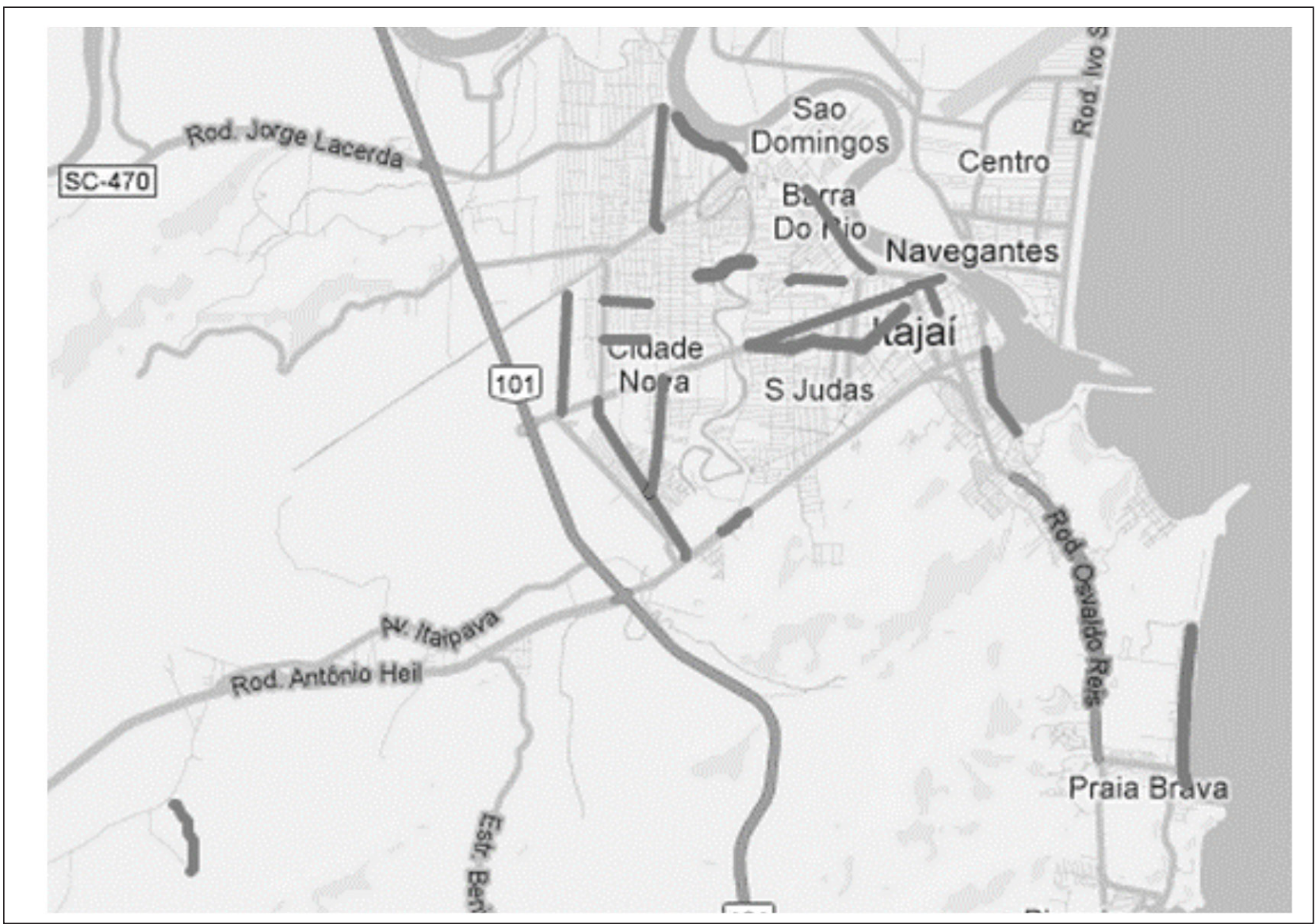

Figura 4 - Sistema cicloviário existente em Itajáí-SC.

Fonte: CICLOAÇÃO. 


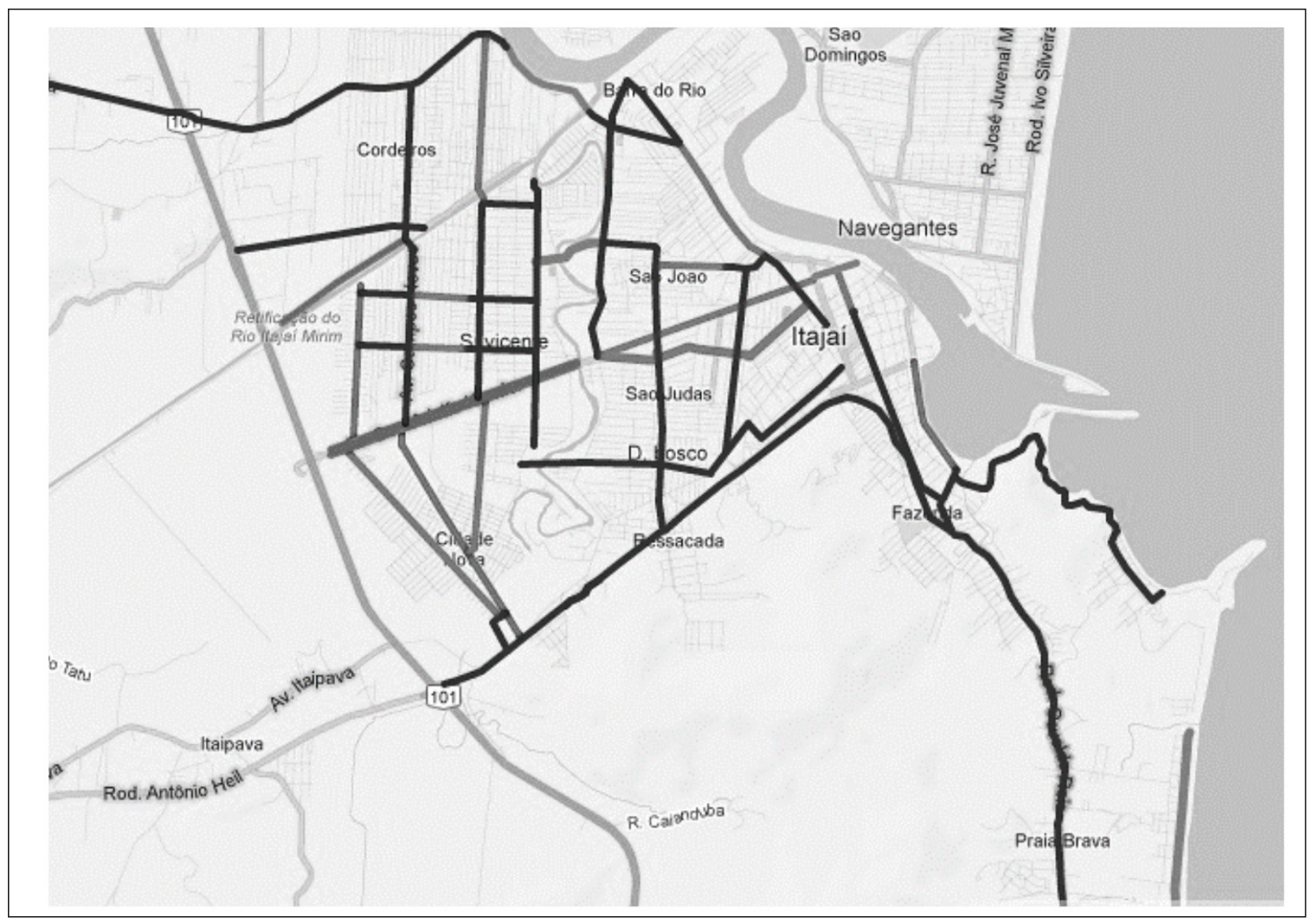

Figura 5- Sistema cicloviário sugerido/projetado para Itajaí-SC.

Fonte: CICLOAÇ̃̃O).

\section{Medidas de conectividade}

Entre as medidas consagradas para a mensuração de conectividade (em diversas áreas, incluindo estudos recentes de conectividade cicloviário) está à utilização de índices matemáticos oriundos da teoria dos grafos. Segundo Feofiloff et al. (2011) a teoria estuda objetos combinatórios - os gráfos que são um modelo adequado para muitos problemas em vários ramos da matemática, da informática, da engenharia e da indústria.

Dentro do sistema de grafos, os segmentos (links) representam a infraestrutura cicloviária (ciclovias, ciclofaixas, rotas, espaços compartilhados) e os vértices (nodes) correspondem as intersecções e pontos finais dentro desta rede de infraestrutura (e.g., cruzamentos ou o ponto final de ciclovias) (Schoner, 2012). O conjunto de dados não contém quaisquer ligações entre a rede cicloviária e o restante da rede rodoviária. Para cada cidade, foi medido o número de vértices (n), número de segmentos (L) e a distância total dos segmentos, ou seja, a extensão da infraestrutura cicloviária.

A metodologia dos grafos é muito difundida na Europa e América do Norte, por exemplo, por retratar de forma simples e com solução analítica matemática simples, o grau de conectividade entre vias, ciclovias, etc. Citam-se como exemplos os estudos de Schoner (2012); Patuelli et al. (2010); Pildes (2014); Tresidder (2005). Em pesquisa (não exaustiva) realizada em estudos técnicos aplicados na mobilidade urbana do Brasil, iniciativas de caráter quantificável, metas de conectividade e de qualidade do sistema cicloviário são muito pouco expressivos.

No caso de um sistema de transportes, pela teoria, a malha é reduzida a uma matriz finita composta por ligações e nós, neste caso bordas e intersecções/ 
pontos de extremidade do sistema viário e cicloviário (Pildes, 2014).

Matematicamente, uma conectividade perfeita teria uma razão ligações/nós de 2,5, o que na prática, para um sistema de transporte é próximo ao inexequível. Segundo Dill (2004) cerca da metade deste valor $(1,4)$ seria uma boa meta para fins de planejamento de uma rede. Estudo de Handy et al. (2003) corroboram com estes valores de referência, apontando que algumas cidades já vêm adotando valores de referência entre 1,2 e 1,4.

A implantação de infraestrutura viária ou clicoviária sem considerar a rede como um sistema integrado e técnicas de aumento da eficiência e conectividade reduz a potencial utilização da infraestrutura de mobilidade. Dessa forma, a teoria dos grafos oferece mensurações da qualidade de uma rede. Levinson \& Schoner (2014) alertam que descontinuidades na rede cicloviária podem ter três potenciais consequências: força o ciclista para tráfego misto; exige longos desvios para evitar o tráfego misto; e ciclistas são desencorajados completamente.

A teoria dos grafos oferece métodos sistemáticos para medir a qualidade de redes que permite uma comparação entre as cidades e visualizar o seu efeito sobre comportamentos de viagens. Kansky (1963 apud Levinson \& Schoner, 2014) apresentou os índices alfa $(\alpha)$ beta $(\beta)$ e gama $(\gamma)$ como taxas que descrevem a relação entre elementos distinguíveis de um gráfico. Atualmente a utilização de medidas da teoria dos gráfos são muito usuais em pesquisa na área de transportes e mobilidade, incluindo por transportes não motorizados (Levinson \& Schoner, 2014). As fórmulas de cálculo e descrição destes parâmetros encontram-se na Tabela 1.

Tabela 1- Descrição dos parâmetros alfa, beta e gama de conectividade.

\begin{tabular}{|c|c|c|}
\hline Índice & Expressão & Descrição \\
\hline Alfa $(\alpha)$ & $\alpha=\frac{L-n+1}{2 n-5}$ & $\begin{array}{l}\text { Avalia o número de ciclos em um grafo em comparação com o número máximo de ciclos. Quanto maior o índice alfa, } \\
\text { mais conectada uma rede está. Redes simples, pouco conectadas possuem valor em torno de } 0 \text {, e o valor } 1 \text { representa } \\
\text { uma rede totalmente conectada. }\end{array}$ \\
\hline $\operatorname{Beta}(\beta)$ & $\beta=\frac{L}{n}$ & $\begin{array}{l}\text { Mede o nível de conectividade num gráfico, e é expressa pela relação entre o número de ligacções (L) sobre o número de } \\
\text { nós (n). Redes simples têm valor menor de l, uma rede conexa tem um valor em torno de l e redes mais complexas } \\
\text { tem um valor maior do que } 1 \text {. Em uma rede com um número fixo de nós, quanto maior é o número de ligaç̃oes, maior } \\
\text { o número de caminhos possíveis na rede. Redes complexas têm um elevado valor de Beta. Baixos valores de beta } \\
\text { significam que ciclistas precisam deslocar-se em vias onde o sistema cicloviário apresenta fragmentações dificultando o } \\
\text { acesso a pontos de interesse. }\end{array}$ \\
\hline $\operatorname{Gama}(\gamma)$ & $\gamma=\frac{L}{3(n-2)}$ & $\begin{array}{l}\text { Considera a relacção entre o número de ligações observadas e o número de ligaç̦ẽes possíveis. } 0 \text { valor de gama situa-se } \\
\text { entre } 0 \text { e 1, onde um valor de } 1 \text { indica uma rede totalmente ligada e seria extremamente improvável na prática. Gama } \\
\text { é um valor eficaz para medir a progressão de uma rede ao longo do tempo, e quanto maior o valor indica que ciclistas } \\
\text { possuem um número maior de escolhas no deslocamento. }\end{array}$ \\
\hline
\end{tabular}

L representa o número de arestas ou conexões entre os nós (links) e R é o número de nós ou intersecç̃oes entre linhas (nodes).

Fonte: adaptado de Ducruet \& Rodrigue (2013).

Os índices $\alpha, \beta$, e $\gamma$ foram calculados para cada cidade, baseada nos métodos de Ducruet \& Rodrigue (2013), Rodrigue et al. (2006); Dill (2004) (Tabela 1).

As Figuras 6 e 7 apresentam o exemplo de aplicação da metodologia nos Estados Unidos, para o município de Glendale, Califórnia, com cerca de 200 mil habitantes, onde foi realizado mapeamento das ligações e nós com o intuito de avaliar a conectividade do sistema cicloviário, e compará-lo com outras cidades norte-americanas. 


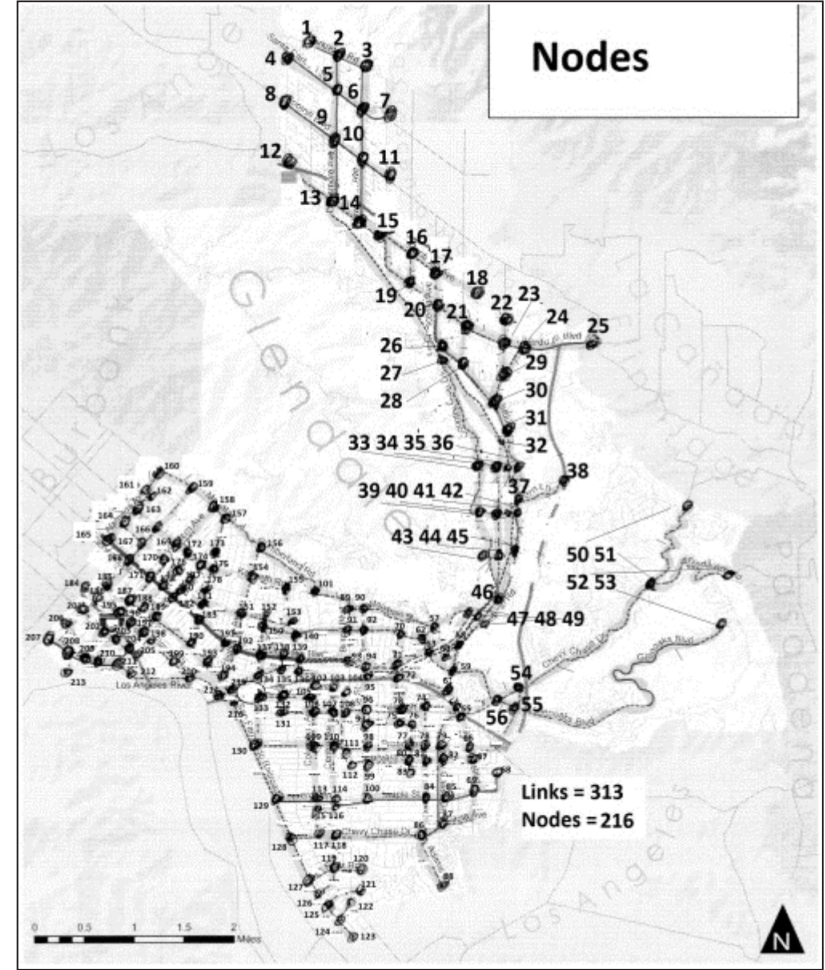

Figura 6 - Nós (n) da rede cicloviária da cidade de Glendale/USA. Fonte: WBG, 2015.

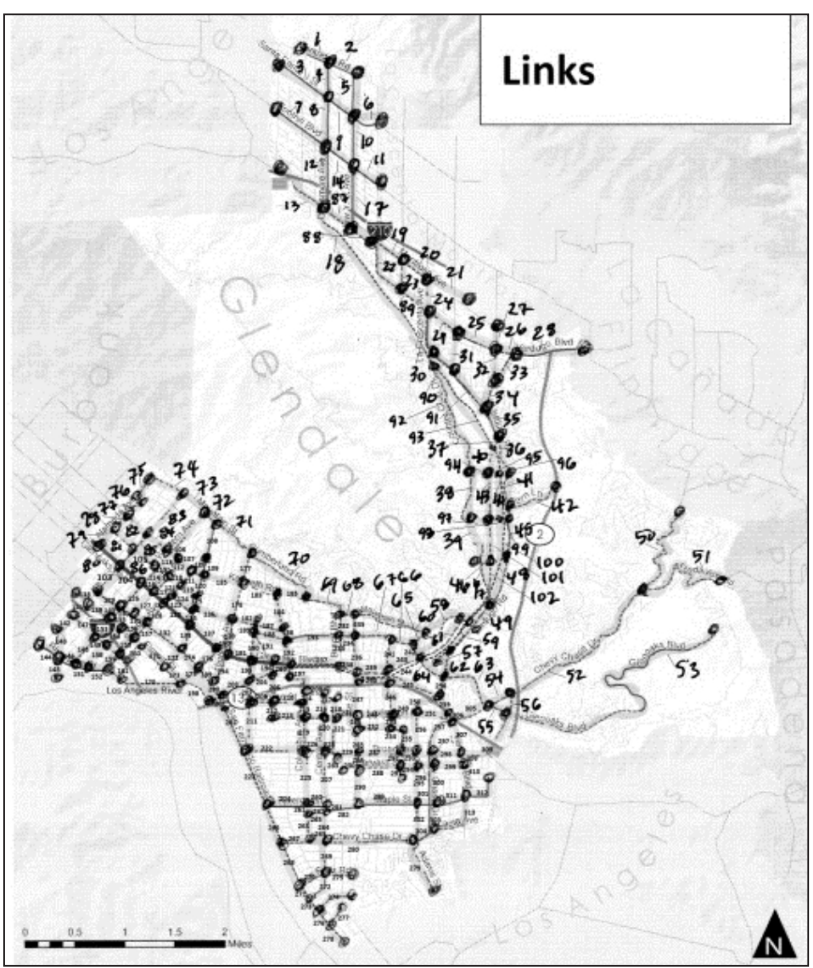

Figura 7 - Ligaç̃os (L) da rede cicloviária da cidade de Glendale/USA. Fonte: WBG, 2015.
No estudo foi constatado que, apesar dos índices de conectividade da rede cicloviária estarem abaixo da média das cidades americanas, o município tem potencial para elevar seus índices para a melhor colocação dentre as cidades analisadas, mediante a implantação do projeto proposto (Tabela 2).

Tabela 2 - Comparacãa dos índices de conectividade da rede cicloviária de Glendale/EUA e outras cidades.

\begin{tabular}{ccccc}
\hline & $\begin{array}{c}\text { Comprimento } \\
\text { Parâmetro }\end{array}$ & & & \\
& $\begin{array}{c}\text { dicloviária } \\
(\mathbf{k m})\end{array}$ & Alfa & Beta & Gama \\
\hline Glendale (atual) & 47,35 & $-0,13$ & 0,72 & 0,25 \\
\hline Glendale (proposto) & 164,15 & 0,23 & 1,45 & 0,49 \\
\hline Média de 72 cidades nos EUA & 311,16 & 0,03 & 0,81 & 0,29 \\
\hline Desvio Padrão & 450,24 & 0,05 & 0,2 & 0,05 \\
\hline Mínimo das 72 cidades dos EUA & 1,54 & $-0,07$ & 0,5 & 0,19 \\
\hline Máximo das 72 cidades dos EUA & $2.204,2$ & 0,17 & 1,28 & 0,43 \\
\hline
\end{tabular}

Fonte: WBG, 2015.

\section{Parâmetros técnicos propostos}

Fragmentação do sistema cicloviário $(f)$

Este indicador foi elaborado no estudo com o objetivo de estimar medidas que venham exprimir a continuidade das ciclovias, assim como a eficiência dessas em termos de integração de pontos estratégicos da cidade por meio de vias arteriais e/ou coletoras.

Em acordo com conceitos de Krizek \& Roland (2004) a fragmentação ou descontinuidade representa pontos onde à via cicloviária termina formando segmentações da pista, sendo fundamental para o entendimento das fragilidades da infraestrutura cicloviária.

Desta forma, foi proposta aqui, uma metodologia quantitativa, com a padronização de medidas para a avaliação desta característica. Nesses termos, pode ser deduzido um grau de fragmentação das ciclovias, dado pelo inverso do número 
de trechos de ciclovias existentes na área de vizinhança em estudo, na forma de:

$$
f=\frac{1}{n_{t}}
$$

Onde: $f=$ é o fator de fragmentação da ciclovia e $\mathrm{n}_{\mathrm{t}}=$ é o número de trechos existentes de rede cicloviária. Essa equação permite uma variação de $f$ entre 0 e 1 , onde 0 é a inexistência do fator (ciclofaixa) e 1 seria uma rede cicloviária totalmente conectada.

\section{Eficiência dos sitema cicloviário $(\in)$}

0 índice de fragmentação, dado pelo $f$, deve ser empregado com cautela uma vez que pode mascarar único trecho isolado de ciclovia como um resultado positivo. Para tal, buscou-se incluir a conectividade de trechos estratégicos da cidade (vias principais), e assim, verificar uma melhor aproximação na eficiência da infraestrutura cicloviária existente.

Não se espera que cada via de uma cidade seja contemplada com uma faixa cicloviária associada. Dessa forma, foi trabalhado com o conceito de vias principais, ou seja, vias coletoras e arteriais ou estruturais, vias que representam uma conexão ampla entre as diferentes localidades em uma cidade. Dessa forma foi aplicado a seguinte relação:

$$
\epsilon=\frac{N_{c}}{N_{T}} f
$$

Onde: $\in$ é a eficiência do transporte por sistema cicloviário; $f=$ é o fator de fragmentação da rede cicloviária; $n_{T}=$ é o número de vias principais (arteriais ou coletoras) existentes em determinada área geográfica; $n_{c}=$ número de vias principais com a presença de infraestrutura cicloviária.

Essa equação permite uma variação entre 0 e 1. Um valor de zero consiste na inexistência do fator (ausência de sistema cicloviário) e 1 seria a presença de infraestrutura cicloviária em todas as vias principais da localidade e com total continuidade destas (sem fragmentação).

\section{Densidade do sistema cicloviário}

Autores definem a densidade do sistema cicloviário pela quantidade de metros lineares de ciclovias por unidade de área urbana (em termos unitários a relação forneceria a relação de distância por área - km/km²), como Ramos (2005); Braga (2015); Programa Cidades Sustentáveis (2016). Esta definição, entretanto, não leva em conta a densidade do sistema viário existente, uma vez que a maioria da infraestrutura cicloviária acompanha a malha viária urbana ou rodoviária (BRASIL, 2007), e, tampouco considera a dimensão dos quarteirões.

Uma medida alternativa da densidade cicloviária pode ser estimada pela extensão do sistema cicloviário relacionada com a extensão do sistema viário. Em termos matemáticos, pode ser proposto por:

$$
D=\frac{L_{c}}{L_{v}}
$$

Onde $L_{c}$ o representa a extensão do sistema cicloviário (em km) e $L_{v}$ a extensão do sistema viário (em km).

Esta relação fornece uma relação adimensional $(\mathrm{km} / \mathrm{km})$, que naturalmente terá uma amplitude no intervalo de 0 a 1 , onde o valor 1 seria o valor máximo, com acompanhamento cicloviário em cem por cento das vias de rolagem. Multiplicando-se o valor por cem, tem-se o índice em porcentagem, representando assim, o total da cobertura da malha cicloviária relativa ao sistema viário.

Esta relação pode ainda ser desagregada espacialmente, considerando-se os quantitativos para vias coletoras e vias arteriais. A intenção neste momento foi a proposição de escalas para o monitoramento do sistema cicloviário, ou seja, a criação de índice que permita a comparabilidade e, de forma objetiva, auxiliar no planejamento, priorizações e para à tomada de decisão, levando-se em consideração que vias coletoras e arteriais possuem um maior fluxo e são assim denominadas pelo posicionamento estratégico na malha viária e capacidade de fluxo, aptas a conectar regiões da cidade e comportar maiores fluxos de tráfego (DNIT, 2010).

0 índice desenvolvido (apresentado a seguir) é baseado na densidade do sistema cicloviário. Dessa forma, calcula-se a densidade do sistema cicloviário 
(d) para vias coletoras e arteriais (vias principais), somados, pela razão entre a extensão cicloviária $\left(L_{c p}\right)$ e a extensão do sistema viário coletor e arterial $\left(L_{a c}\right)$, ambas dadas em quilômetros. E expressão é mostrada abaixo:

$$
d=\frac{L_{c p}}{L_{a c}}
$$

Recomenda-se que a determinação do $L_{c p}$ não seja rígida, já que devido à conjuntura atual das cidades já estarem consolidadas, por vezes inviabiliza a alocação de infraestrutura cicloviária em vias principais, podendo desta forma, serem implementadas em vias alternativas, paralelas ao sistema viário de maior hierarquia.

Com este indicador elaborado, é possível determinar as escalas de atendimento, ou seja, o quão realmente o sistema cicloviário estará contribuindo para a qualificação da mobilidade urbana. Teoricamente, segundo Dill \& Carr (2003); Pucher \& Buehler (2006) quanto maior a quantidade de ciclovias e ciclofaixas, maior o número de pessoas dispostas a utilizarem a bicicleta como transporte, maior a segurança destes ciclistas, menor a pressão do trânsito gerada por veículos automóveis, além de outros benefícios associados à saúde e sustentabilidade. A literatura aponta diversos casos que corroboram com estes benefícios, como as pesquisas de Minano \& Santos (2015); Parker \& Gustat \& Rice (2011) ou Litman (2010). Este último, por exemplo, apresenta quantificações financeiras dos benefícios gerados por transportes não motorizados.

\section{Índice de Mobilidade Cicloviária (IMCiclo)}

Apesar das ressalvas da construção de índices, estes se mostram muito úteis de para o monitoramento de diferentes áreas do conhecimento, permitindo, prontamente, uma elucidação das questões de interesse (Jannuzzi, 2002; Siche, et al. 2007). Como exemplo, citam-se: IDH (Índice de Desenvolvimento Humano), IMC (Índice de Massa Corporal), Índice de Gini, e tantos outros utilizados por profissionais e governos, e que considerando suas limitações, tornam-se positivos tanto para o planejamento e metas, como para o controle social e divulgação de progressos em determinada área.

Tendo isso por base, foi estabelecida uma simples relação considerando os principais aspectos da mobilidade cicloviária elencados pela pesquisa, utilizando os seguintes indicadores:

- $f$ (índice de fragmentação): inclui efeitos da fragmentação das vias cicloviárias;

- $d$ (densidade do sistema cicloviário): inclui a extensão do sistema cicloviário;

- $\gamma$ (índice gama): inclui os efeitos de conectividade (teoria dos grafos), ressaltando o número de escolhas possíveis no trajeto.

A relação é mostrada pela equação abaixo:

$$
\text { IMCiclo }=100 f d \gamma
$$

Ambos indicadores possuem uma amplitude de 0 a 1, mantendo o efeito para o índice resultante, onde o valor de 1 representa o valor máximo para cada índice (1), o que representaria uma cobertura perfeita na malha cicloviária, sem fragmentações, em $100 \%$ das vias principais e com traçados de conectividades máximas nas vias.

A multiplicação do índice por 100 além de dar ao índice característica percentual, possui o objetivo de evitar números pequenos. Por exemplo, uma cidade com índices de $d$, $f$ e $\gamma$ de 0,3 cada um, resultariam em um IMCiclo de 0,027, multiplicando-se então por 100 , resulta em $2,7 \%$.

De forma qualitativa, o indicador pode ser interpretado a partir de classes, que são interessantes do ponto de vista da gestão e da disseminação popular dos resultados. Para o presente trabalho foram propostas seis classes com base na combinação igual entre as variáveis, por exemplo, valores de IMCiclo acima de 30 significam que todos os índices atingiram próximo a 0,7 , significando uma efetividade muito expressiva do ponto de vista operacional e funcional em uma cidade.

Já valores de IMCiclo até 3 , resultariam de valores de e de 0,3, aproximadamente, o que mostra uma estruturação existente do sistema cicloviário na cidade, entretanto, ainda carece de melhorias no que diz respeito a cobertura, fragmentação e conectividade (Tabela 3). 
Tabela 3 - Classificaçã̃o do IMCiclo.

\begin{tabular}{|c|c|c|}
\hline Valor do IMCiclo & Categoria & Descrição \\
\hline$<1$ & Pontual ou inexistente & Indica uma presença isolada de ciclovias/ciclofaixas apenas em algumas vias, ou apenas como uso recreacional. \\
\hline entre $1-3$ & Insuficiente & Indica a existência razoável de ciclovias ou ciclofaixas, porém indica alta fragmentação destas. \\
\hline entre 3-10 & Baixo & $\begin{array}{l}\text { Indica a existência razoável de ciclovias ou ciclofaixas, porém ainda são observadas fragmentações que possam baixar quali- } \\
\text { dade da mobilidade cicloviária. }\end{array}$ \\
\hline entre $10-20$ & Regular & $\begin{array}{l}\text { Indica nível alto de cobertura, mostrando um amadurecimento do município ao tratar das questões alternativas de mobilidade } \\
\text { urbana, mas a presença de fragmentações ainda restringe a mobilidade. }\end{array}$ \\
\hline Entre 20-30 & Adequado & $\begin{array}{l}\text { Indica nível avançado de cobertura, mostrando um amadurecimento do município ao tratar das questões alternativas de mobi- } \\
\text { lidade urbana, mas a presença de fragmentações ainda restringe a mobilidade em determinados pontos. }\end{array}$ \\
\hline$>30$ & Ótimo & $\begin{array}{l}\text { Indica que a infraestrutura cicloviária no município possui importância comparável a de veículos automotores, com níveis de } \\
\text { funcionalidade e sustentabilidade altos. }\end{array}$ \\
\hline
\end{tabular}

Fonte: 0 autor.

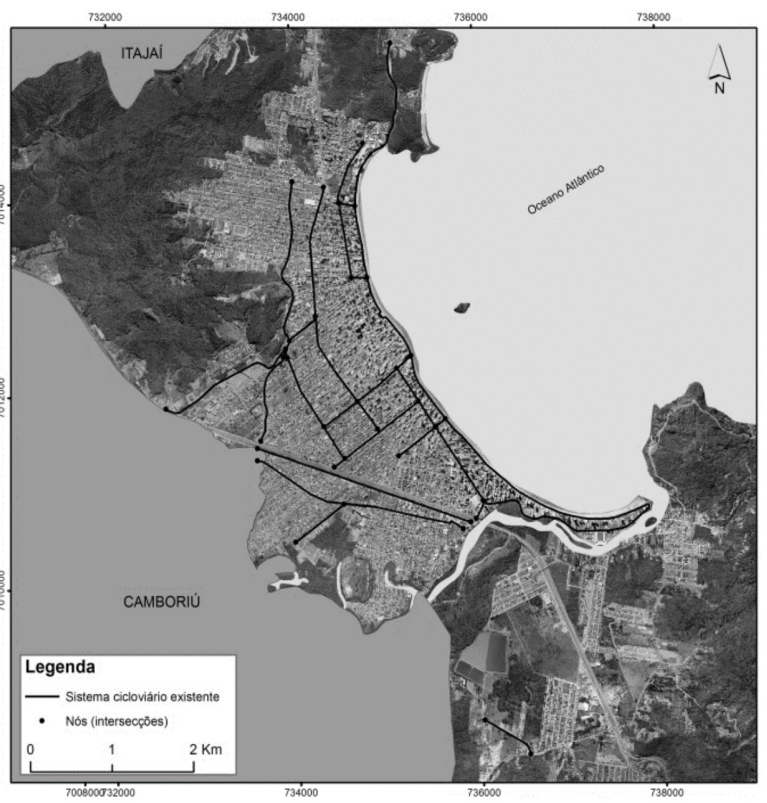

Figura 8 - Links e nós do sistema cicloviário existente em Balneário Camboriú.

Fonte: 0 autor.

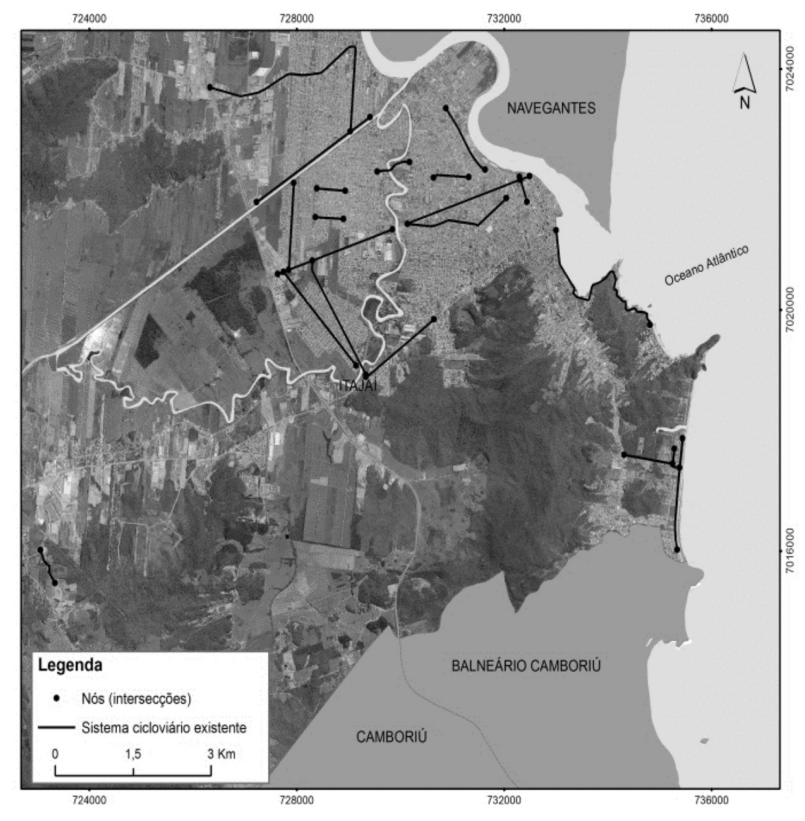

Figura 9 - Links e nós do sistema cicloviário existente em Itajaí. Fonte: 0 autor. 


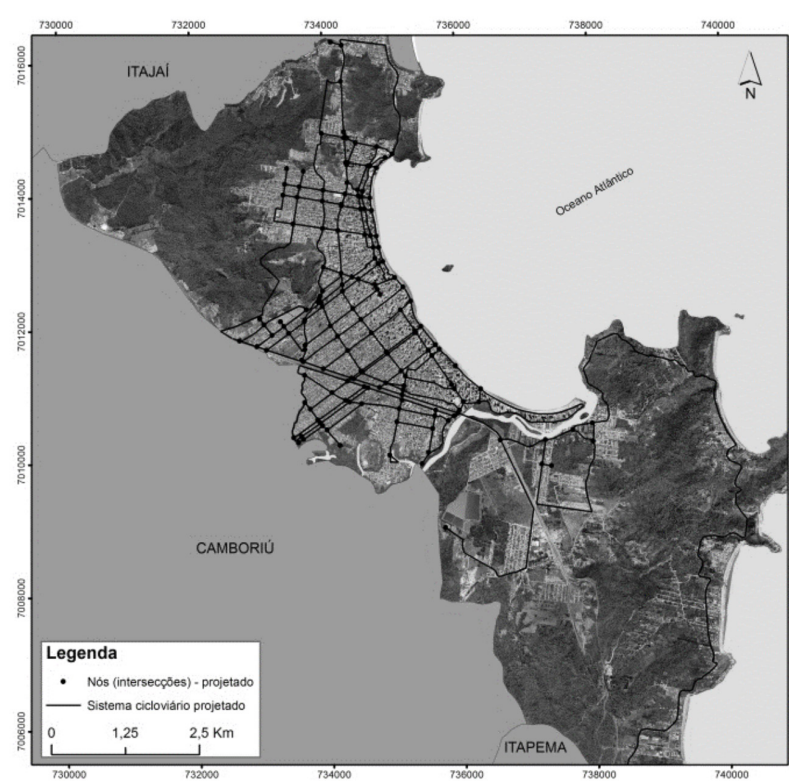

Figura 10 - Links e nós do sistema cicloviário projetado para Balneário Camboriú.

Fonte: 0 autor.

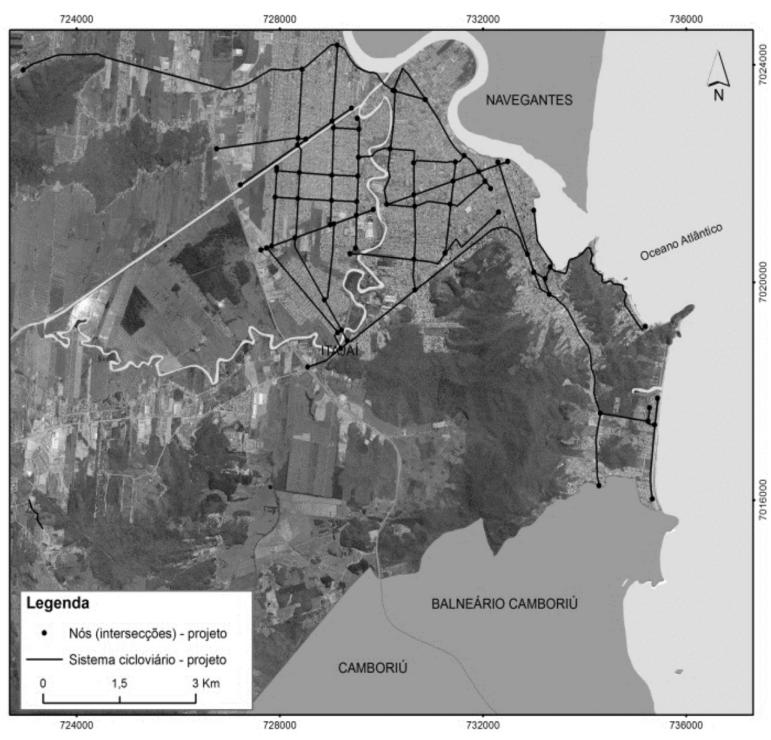

Figura 11- Links e nós do sistema cicloviário projetado para Itajaí.

Fonte: 0 autor.

\section{Índice de Fragmentação $(f)$}

0 índice de fragmentação $(f)$, definido como o inverso do número de fragmentos (trechos com estrutura ciclística isoladas) permite que seja construída uma curva de referência para valores pré-definidos de fragmentos. A curva possui um valor máximo de 1 , o que indica um sistema sem fragmentação, e o valor mínimo tende a zero (vide Figura 12). Quanto menor o valor, maior o número de trechos sem comunicação entre si.

No estudo de caso proposto para as cidades de Itajaí e Balneário Camboriú foi constatado que a malha cicloviária de Balneário Camboriú possui menos fragmentações, quatro conjuntos cicloviários, contra onze no município de Itajaí, resultando em valores de $f$ de 0,25 e 0,091 respectivamente.

Considerando um cenário de evolução, a partir da implementação dos projetos futuros, ambos municípios reduzirão consideravelmente a fragmentação do sistema cicloviário, atingindo o valor de $f$ igual a 0,5 , ou seja, o sistema cicloviário será constituído por dois conjuntos.

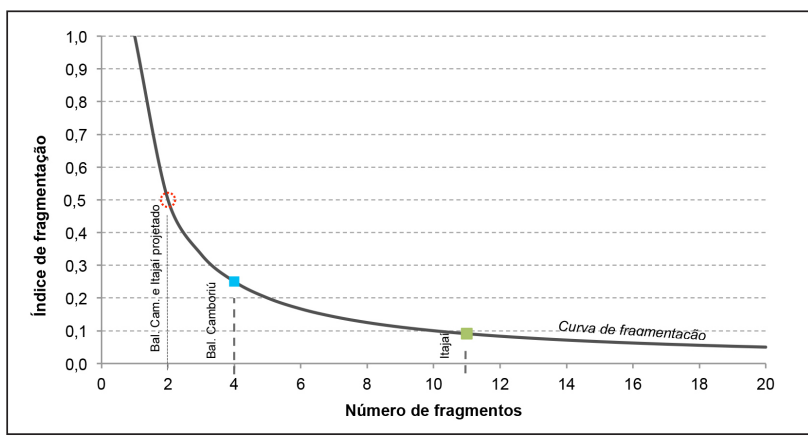

Figura 12 - Curva de fragmentação do Índice de Fragmentação $(f)$ e exemplos para as cidades de Balneário Camboriú e Itajaí em Santa Catarina considerando o cenário atual e futuro a partir da implementação dos projetos. Fonte: 0 Autor.

\section{Índice de eficácia do sistema cicloviário $(\in)$}

O indicador mostrou aderência para uma situação real, sendo constatado que ambos municípios possuem defasagens na questão da implantação de malha cicloviária em vias de maior circulação (vias arteriais e coletoras), que permitem um maior deslocamento de pessoas e veículos ou que são importantes conectoras de diferentes localidades de uma cidade.

0 estudo apontou que Itajaí possui aproximadamente 29\% das vias coletoras/arteriais com infraestrutura cicloviária e Balneário Camboriú cerca de 35\%. Esses dados refletem no índice de eficácia proposto, o qual combina a proporção de vias principais com infraestrutura cicloviária, com a fragmentação desta. Com isso o índice rendeu valores de $\in$ entre 
0,03 e 0,09 para Itajaí e Balneário Camboriú, respectivamente, o que indica uma maior estruturação do sistema cicloviário em Balneário Camboriú (Tabela 4).

Tabela 4 - Índice de eficácia do sistema cicloviário $(\in)$.

\begin{tabular}{c|c|ccc}
\hline \multirow{2}{*}{ Parâmetro } & \multicolumn{2}{|c}{ Atual } & \multicolumn{2}{c}{ Projetado } \\
\cline { 2 - 5 } & Itajaí & $\begin{array}{r}\text { Balneário } \\
\text { Camboriú }\end{array}$ & Itajaí & $\begin{array}{c}\text { Balneário } \\
\text { Camboriú }\end{array}$ \\
\hline$N_{c}$ & 21 & 17 & 39 & 46 \\
\hline$N_{t}$ & 73 & 48 & 73 & 58 \\
\hline$f$ & 0,09 & 0,25 & 0,5 & 0,5 \\
\hline$\in$ & $\mathbf{0 , 0 3}$ & $\mathbf{0 , 0 9}$ & $\mathbf{0 , 2 7}$ & $\mathbf{0 , 4 0}$ \\
\hline
\end{tabular}

Fonte: 0 Autor.

Considerando a implantação dos projetos futuros, a cobertura das vias principais com ciclovias aumentará para 53\% e 79\% para Itajaí e Balneário Camboriú, respectivamente. Isso refletirá positivamente no, aumentando o índice para 0,27 e 0,4 para Itajaí e Balneário Camboriú, respectivamente.

\section{Densidade do sistema cicloviário (d)}

A densidade é um parâmetro chave, uma vez que retrata uma situação prática de fácil entendimento, ou seja, a cobertura da cidade com infraestrutura cicloviária instalada. Sua construção depende apenas das medidas de extensão do sistema viário e cicloviário. Recomenda-se ainda, que o indicador seja utilizado considerando-se dados referentes ao perímetro urbano, para evitar interpretações diferentes para municípios com grande extensão territorial rural.

Para as cidades em estudo os indicadores apontaram uma diferença entre as cidades de $4,6 \%$ considerando a extensão total do sistema viário e de 10,4\% considerando o sistema viário principal. Balneário Camboriú mantém os melhores índices, possuindo uma cobertura de cerca de $10 \%$ da rede viária, e $30 \%$ considerando o sistema viário principal, contra 5,8\% e 19,5\%, para Itajaí, respectivamente, como mostrado pela Tabela 5.

No caso dos projetos futuros, foi possível comparar a evolução da densidade do sistema cicloviário junto às vias principais dos municípios. Esta respondeu positivamente, mostrando que com a expansão da malha cicloviária em Balneário Camboriú para aproximadamente $104 \mathrm{~km}$, a cobertura nas vias principais passará para cerca de 80\%. Para Itajaí, o traçado proposto prevê uma expansão para aproximadamente $77 \mathrm{~km}$ de rede cicloviária, fornecendo uma densidade de cobertura de $45,2 \%$ para as vias principais.

Tabela 5 - Densidade do sistema cicloviário em Balneário Camboriú/SC e Itajaí/SC.

\begin{tabular}{|c|c|c|c|}
\hline \multicolumn{4}{|c|}{ Sistema cicloviário existente } \\
\hline Indicadores & Variável/unidade & Balneário Camboriú & Itajai \\
\hline Extensão sistema viário urbano & $L_{v}(k m)$ & 329,6 & 573,9 \\
\hline Extensão viária principal & $L_{o c}(k m)$ & 114,5 & 169,7 \\
\hline Extensão sistema cicloviário & $L_{c}(\mathrm{~km})$ & 34,2 & 33,1 \\
\hline Densidade cicloviário (total de vias) & $D(\mathrm{~km} / \mathrm{km})$ & $10,4 \%$ & $5,8 \%$ \\
\hline Densidade do cicloviário (vias principais) & $\mathrm{d}(\mathrm{km} / \mathrm{km})$ & $29,9 \%$ & $19,5 \%$ \\
\hline \multicolumn{4}{|c|}{ Sistema cicloviário projetado } \\
\hline Indicadores & Variável/unidade & Balneário Camboriú & Itajaí \\
\hline Extensão viária principal projetado & $\mathrm{L}_{\mathrm{oc}}(\mathrm{km})$ & 129,9 & 169,7 \\
\hline Extensão sistema cicloviário projetado & $\mathrm{L}_{\mathrm{c}}(\mathrm{km})$ & 103,8 & 76,7 \\
\hline Densidade do cicloviário principal & $\mathrm{d}(\mathrm{km} / \mathrm{km})$ & 79,9 & $45,2 \%$ \\
\hline
\end{tabular}

Fonte: 0 Autor. 


\section{Alfa, Beta e Gama (Teoria dos gráfos)}

Os resultados do cálculo dos índices são apresentados nas Figuras 13 e 14. Os maiores valores são observados em Balneário Camboriú, atingindo $0,04,1,05$ e 0,37 , respectivamente para alfa, beta e gama. Entretanto, não indica uma conectividade ideal, haja visto, por exemplo, que os valores de alfa e gama variam de 0 a 1 . Com a implantação dos projetos futuros os índices responderão positivamente, atingindo valores de 0,29, 1,57 e 0,53, respectivamente para alfa, beta e gama. Reitera-se, segundo Handy et al. (2003) valores de beta ( $\beta$ ) acima de 1,2 conferem a rede uma boa conectividade.

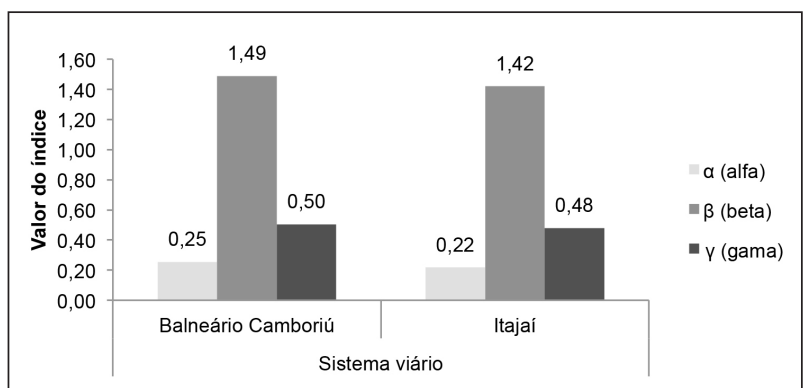

Figura 13 - Índices alfa, beta e gama para Balneário Camboriú, Itajaí. Fonte: 0 Autor.

Quando comparada a conectividade do sistema cicloviário e do sistema viário observa-se uma pequena diferença (Figura 14). Dessa forma, como o sistema cicloviário usualmente está associado as vias de tráfego, a melhoria da conectividade também passaria por reestruturação do sistema viário. Entretanto, esta é uma alternativa dispendiosa, devido, principalmente as cidades já estarem consolidadas, por vezes de forma desordenada, que dificulta intervenções desta magnitude. Assim, estratégias para o incremento da conectividade podem ser feitas através de rotas em vias locais, ou criação de ciclovias independentes do sistema viário, por entre quarteirões.

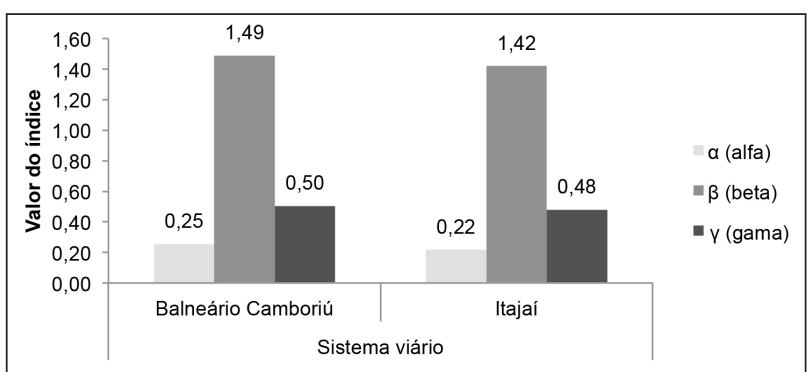

Figura 14 - Índices alfa, beta e gama para o sistema viário principal de Balneário Camboriú e Itajaí.

Fonte: 0 Autor.

\section{IMCiclo}

O Índice de Mobilidade Cicloviária (IMCiclo) proposto resulta da combinação da densidade de cobertura, índice gama de conectividade e a fragmentação do sistema cicloviário. Ressalta-se que no caso da densidade, utilizar-se-á o valor relativo ao sistema viário principal, não sendo abordado a totalidade do sistema viário. 0 índice é dado pela expressão: IMCiclo $=100 \mathrm{fd} \gamma$.

O IMCiclo mostrou-se sensível nas avaliações realizadas, sendo observado uma melhoria significativa a partir da ampliação das redes nas cidades em estudo. Balneário Camboriú possui os melhores índices na comparação, com um valor de IMCiclo atual de $2,8 \%$ e de $21,2 \%$ a partir da execução do projeto futuro, ou seja, atingindo uma classificação de: Adequado, segundo a metodologia proposta. No caso de Itajaí, a partir do cenário de proposto a classificação passaria de Pontual para Regular, tal como mostrado pela Figura 15.

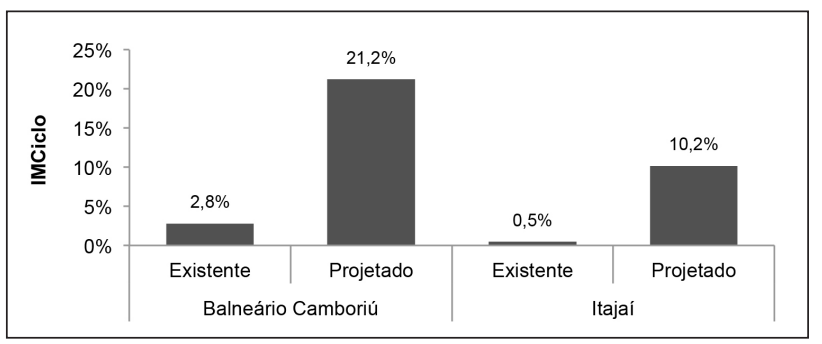

Figura 15 - Síntese dos resultados dos índices calculados para Balneário Camboriú e Itajaí.

Fonte: 0 Autor.

\section{Conclusão}

O uso de bicicletas deve ser compreendido, além de seu uso recreativo, já sendo consagrada como um meio eficiente de mobilidade em muitos países com vasta experiência no uso do modal. Para tal, uma rede cicloviária deve ser estudada e planejada de forma técnica-participativa, compartilhando a infraestrutura urbana com veículos e pedestres, com segurança e responsabilidade.

O objetivo desta pesquisa foi trazer um arcabouço técnico que auxilie tomadores de decisão e a sociedade civil a buscar um conhecimento mais aprofundado no que se refere melhoria da mobilidade urbana com enfoque no modal cicloviário. Que os 
parâmetros aqui apresentados propostos venham a contribuir para o amadurecimento da sociedade e dos governos para uma expansão da participação de veículos não-motorizados entre os modais de transporte.

No que se refere ao desempenho das cidades estudadas, a situação atual da rede cicloviária mostra defasagens em ambas, no que se refere a extensão disponível, conectividade, sobretudo em Itajaí. Entretanto, a partir da implementação dos traçados propostos, espera-se uma melhora significativa nos indicadores, o que na prática proporcionará mais rotas disponíveis, possível adesão de novos usuários, melhoria nas condições de segurança para pedestres e ciclistas, e consequente melhoria na mobilidade urbana dos municípios.

Os indicadores utilizados e desenvolvidos se mostraram eficazes, ao traduzir a situação da infraestrutura cicloviária das cidades estudadas, e até subsidiar políticas públicas. No caso do IMCiclo, mesmo obtendo-se resultados factíveis, recomenda-se a sua execução para outros municípios, a fim de melhorar a comparabilidade dos municípios, e até possíveis ajustes nas classes propostas.

Como recomendações cita-se a criação de índices de potencial uso de bicicletas como modal alternativo de tráfego. A forma mais efetiva de construir um parâmetro nesse sentido é por meio de pesquisas de origem-destino, onde o entrevistado é questionado sobre características de seu deslocamento habitual e do interesse deste em utilizar bicicletas.

Da mesma forma, observa-se que a complementação de um estudo quantitativo é o estudo qualitativo. Desta forma, análises sobre as condições das ciclovias, sinalização, segurança, existência de para-ciclos, conflitos de uso do espaço, fluxo (quantidade de usuários), capacidade das faixas (velocidade média de deslocamento), etc. poderiam ser integrados de forma sistêmica. Isso permitiria uma análise efetiva das condições do sistema viário, localizando as vulnerabilidades e subsidiando a implementação de medidas para aumentar a eficiência no deslocamento, etc.

\section{Referências}

Allis, T. (2015). Sobre cidades, bicicletas e turismo: evidências na propaganda imobiliária em São Paulo. Caderno Virtual de Turismo, 15(3), 390-406.

Braga, R. (2016). Indicadores de sustentabilidade para avaliação de zonas especiais de interesse social (ZEIS) para implantação de habitação social na cidade de Piracicaba-SP. Caderno de Geografia, 26(46).

Brasil. (1997, 23 de Setembro). Lei n. 9.503, de 23 de Setembro de 1997. Institui o Código de Trânsito Brasileiro.

Brasil. (2012, 03 de Janeiro). Lei n. 12.587, de 3 de Janeiro de 2012. Institui as diretrizes da Política Nacional de Mobilidade Urbana.

CET - Companhia de Engenharia de Tráfego. Bicicleta: Definições. Recuperado em junho de 2016, de http://www. cetsp.com.br/consultas/bicicleta/definicoes.aspx.

Dill, J. (2004). Measuring Network Connectivity for Bicycling and Walking. TRB. http://reconnectingamerica.org/assets/ Uploads/TRB2004-001550.pdf. League of Illinois Bicyclists. Portland,.

Dill, J., \& Carr, T. (2003). Bicycle Commuting and Facilities in Major U.S. Cities: If You Build Them, Commuters Will Use Them - Another Look. Portland State University. TRB Annual Meeting.

Departamento Nacional de Infraestrutura de Transportes DNIT (2010). Manual de projeto de geométrico de travessias urbanas. Brasília: Ministério dos Transportes. Recuperado em 12 de janeiro de 2016, de http://ipr.dnit.gov.br.

Ducruet C., \& Rodrigue J. P. (2013). Graph Theory: Measures and Indices. The geography of transport systems. Third edition. Jean-Paul Rodrigue, New York: Routledge, 416 pages. ISBN 978-0-415-82254-1.

Feofiloff, P; Kohayakawa, Y.; Wakabayashi, Y. (2011). Uma introdução sucinta à teoria dos grafos. São Paulo. Recuperado em julho de 2015, de http://www.ime.usp.br/ pf/teoriadosgrafos/texto/TeoriaDosGrafos.pdf.

Gondim, M.F. (2010). Cadernos de desenho:ciclovias. Rio de Janeiro: Editora COPPE/UFRJ.

Handy, S., Butler, K.; \& Paterson, R. G. (2003). Planning for Street Connectivity - Getting from Here to There, American Planning Association, Chicago. 
Laboratório de Transportes e Logística - LABTRANS. (2012). Ciclovia, ciclofaixa, ciclorrota e espaço compartilhado. Universidade Federal de Santa Catarina. Recuperado em dezembro de 2015, de https://www.labtrans.ufsc. $\mathrm{br} / \mathrm{PSR} /$ post/Ciclovia-ciclofaixa-ciclorrota-e-espacocompartilhado.aspx.

Lee, A. (2008). What is the economic contribution of cyclists compared to car drivers in inner suburban Melbourne's shopping strips? The University of Melbourne. Melbourne. Recuperado em julho de 2015, de http://colabradio.mit. edu/wp-content/uploads/2010/12/Final_Thesis_Alison_ Lee.pdf.

Litman, T. (2010). Quantifying the Benefits of Nonmotorized Transportation for Achieving Mobility Management Objectives. Victoria Transport Policy Institute. Victoria. Recuperado em julho de 2015, de http://artshenkman. com/cs/groups/content/@webottawa/documents/pdf/ mdaw/mdy3/ edisp/con056214.pdf.

Jannuzzi, P. M. (2002). Considerações sobre o uso, mau uso e abuso dos indicadores sociais na formulação e avaliação de políticas públicas municipais. Revista de Administração Pública - RAP, 36(1), 51-72.

Krizek, K. J., \& Roland, R. W. (2004) What is at the end of the road? Understanding discontinuities of on-street bicycle lanes in urban settings. Transportation Research. Part D 10 (2005) 55-68, Minneapolis.

Marlin, J. W. (2008). Bicycle Transportation Issues: Describing the Attitudes and Opinions of Cyclists in Austin, Texas. (Masters of Public Administration). Texas State University, Austin, Texas.

Maruyama, C. M., \& Simões, F. A. (2014). Arborização urbana e transporte cicloviário: o caso de Chapecó, SC. Revista dos Transportes Públicos - ANTP - Ano 36. 2º quadrimestre. Chapecó.

Minano, M. P.\& Santos, A. (2015). Contribuição dos serviços de bicicleta compartilhada na mobilidade sustentável no Brasil. Congresso Brasileiro de Transporte e Trânsito. ANTP. Santos-SP (Brasil).

Ministério das Cidades. (2007). Caderno de Referência para elaboração de: Plano de Mobilidade por Bicicleta nas Cidades. Brasília: Ministério das Cidades. Recuperado em 17 de outubro de 2016, de http://www.cidades.gov.br.
Neckel, A. et.al. (2015). Sugestões para o sistema cicloviário: uma proposta para o uso da bicicleta no beneficiamento dos fatores de mobilidade urbana na cidade de Passo Fundo/ RS-Brasil. VI Congresso Brasileiro de Gestão Ambiental. Porto Alegre.

NITC - National Institute for Transportation and Communities (2014). Lessons from the green lanes: evaluating protected bike lanes in the U.S. Final report NITCRR-583. Portland State University. Portland.

NYC - New York City. (2012). Measuring the Street: New Metrics for 21st Century Streets. New York. Recuperado em junho de 2015, de http://www.nyc.gov/html/dot/downloads/pdf/2012-10-measuring-the-street.pdf

Parker, K. M.; Gustat, J., \& Rice, J. (2011). Installation of Bicycle Lanes and Increased Ridership in an Urban, MixedIncome Setting in New Orleans, Louisiana. Journal of Physical Activity and Health. S98-S102. Human Kinetics,

Patuelli, R.; Reggiani, A. Nijkamp, P., \& Bade, F. J. (2010). The evolution of the commuting network in Germany Spatial and connectivity patterns. Journal of Transport and Land Use. Minneapolis.

Pildes, R. (2014). Connectivity and Accessibility of UIUC Campus Bike Paths Quantitative Measures for Bicycle Infrastructure. University of Illinois - Urbana Campaign Department of Geography and GIS. Illinois.

PMBC - Prefeitura Municipal de Balneário Camboriú. (2014). Leitura técnica do Plano Diretor Participativo Relatório do Diagnóstico. Produto 03. Balneário Camboriú.

Programa Cidades Sustentáveis. Melhor mobilidade menos tráfego. Ciclovias exclusivas. Recuperado em junho de 2015, de http://indicadores.cidadessustentaveis.org.br/ ciclovias-exclusivas

Pucher, J., \& Beuhler, R. (2006). Why Canadians cycle more than Americans: A comparative analysis of bicycling trends and policies. Transport Policy. 265-279.

Racca, D. P., \& Dhanju, A. (2015). Project Report for Property Value/Desirability Effects of Bike Paths Adjacent to Residential Areas. Delaware Center for Transportation. The State of Delaware Department of Transportation. Newark, 2006. Recuperado em julho de 2015, de http://128.175.63.72/ projects/DOCUMENTS/bikepathfinal.pdf. 
Campos, V. B. G., \& Ramos, R. A. R. (2005). Proposta de indicadores de mobilidade urbana sustentável relacionando transporte e uso do solo. In: Pluris 2005. Primeiro Congresso Luso-Brasileiro para o Planejamento Urbano, Regional, Integrado e Sustentável.

Rau, S. L. (2012). Sistema cicloviário e suas potencialidades de desenvolvimento: o caso de Pelotas/RS. (Dissertação de Mestrado) Universidade Federal de Pelotas. Pelotas.

Schoner, J. E. (2012). The Missing Link: Bicycle Infrastructure Networks and Ridership in 74 US Cities. University of Minnesota. Department of Civil Engineering \& Humphrey School of Public Affairs. Minneapolis.

Siche, R., \& Agostinho, F., \& ORTEGA, E., \& ROMEIRO, A. (2007). Índices versus indicadores: precisões conceituais na discussão da sustentabilidade de países. Ambiente \& Sociedade, X(2), 137-148.

Silva, P. F. S. (2015). Contribuição para uma mobilidade urbana saudável. Mobilize Brasil.

Rodrigue, J. P.; Slack, B., \& Comtois, C. (2006). Transportation and Geography. In The Geography of Transport Systems, 1-37. New York: Routledge.

Transporte Ativo. (2015). Pesquisa Perfil do Ciclista. Parceria Nacional pela Mobilidade. Laboratório de Mobilidade Sustentável do PROURBE-UFRJ e Observatório das Metrópoles. Rio de Janeiro.

Tresidder, M. (2005). Using GIS to Measure Connectivity: An Exploration of Issues. Field Area Paper. School of Urban Studies and Planning. Portland State University.

WBG - Walk Bike Glendale. (2015). How does Glendale's network compare? 03 de Julho de 2015. Recuperado em julho de 2015, de https:// walkbikeglendale.wordpress.com/2015/07/03/ how-does-glendales-bike-network-compare.

Submissão: $12 / 01 / 2016$

Received: $12^{\text {th }}$ January 2016

Aprovação: 24/11/2016

Approved: $24^{\text {th }}$ November 2016

urbe. Revista Brasileira de Gestão Urbana (Brazilian Journal of Urban Management), 2017 set./dez., 9(3), 587-604 